\title{
Experimental Validation of a Highly Damped Deployable Solar Panel Module with a Pogo Pin-Based Burn Wire Triggering Release Mechanism
}

\author{
Shankar Bhattarai, ${ }^{1}$ Ji-Seong Go, ${ }^{1}$ Hongrae Kim, ${ }^{2}$ and Hyun-Ung Oh $\mathbb{D}^{1}$ \\ ${ }^{1}$ Space Technology Synthesis Laboratory, Department of Smart Vehicle System Engineering, Chosun University, 309, Pilmun-daero, \\ Dong-gu, Gwangju 61452, Republic of Korea \\ ${ }^{2}$ Soletop Co. Ltd., 409 Expo-ro, Yuseong-gu, Daejeon, Republic of Korea
}

Correspondence should be addressed to Hyun-Ung Oh; ohu129@chosun.ac.kr

Received 8 September 2020; Revised 22 November 2020; Accepted 4 December 2020; Published 15 December 2020

Academic Editor: Enrico C. Lorenzini

Copyright (c) 2020 Shankar Bhattarai et al. This is an open access article distributed under the Creative Commons Attribution License, which permits unrestricted use, distribution, and reproduction in any medium, provided the original work is properly cited.

In this present work, a highly damped deployable solar panel module was developed for application in the $3 \mathrm{U}$ CubeSat. The solar panel proposed herein is effective in guaranteeing the structural safety of solar cells under a launch environment owing to the superior damping characteristics achieved using multilayered stiffeners with viscoelastic acrylic tapes. A holding and release action of the solar panel was achieved by a new version of spring-loaded pogo pin-based burn wire triggering mechanism. A demonstration model of high-damping solar panel assembly was fabricated and tested to validate the effectiveness of the design. The holding and release mechanism achieved using a pogo pin was functionally tested through solar panel deployment tests under ambient room temperature and a thermal vacuum environment. The design effectiveness and structural safety of the solar panel module were validated through qualification-level launch and in-orbit environment tests.

\section{Introduction}

Since the development of a cube-shaped nanoclass miniaturized satellite by the California Polytechnic State University and Stanford University in 1999 [1], the aerospace community has seen a surge in the development of inexpensive small satellites utilizing these form factors. The simplest platform, known as $1 \mathrm{U}$, is a $10 \mathrm{~cm}$ cube satellite (CubeSat) with a maximum allowable mass of $1.33 \mathrm{~kg}$, although larger configurations [2] are also permissible by stacking the units. CubeSats were primarily envisioned for low-cost educational [3] and scientific [4] missions in universities and research institutions. Although, satellites that utilize this form factor have received considerable attention in the area of space science [5], technology verification [6], meteorology [7], and earth observation [8] owing to the miniaturization of electronics and sensors, the low-cost and short period required for construction and launch, and the availability to launch as a secondary payload. Recently, this trend has been rapidly facilitated by the use of commercial off-the-shelf (COTS) components for electronics and structures to achieve a wide range of operational missions based on CubeSat constellations [9-11] with potential high value in terms of science return and commercial revenue.

In recent years, a $3 \mathrm{U}$ platform with a dimension of three units of $1 \mathrm{U}$, i.e., $10 \mathrm{~cm} \times 10 \mathrm{~cm} \times 34 \mathrm{~cm}$, has become increasingly popular [12] in research laboratories, and small companies have aimed to conduct more advanced scientific missions in a short development timeline. Although, one of the main limitations of the CubeSat bus is the availability of in-orbit power generation capability owing to restrained surface area for solar cell installation; this has become a concern in implementing advanced payloads. The average power obtained on a $3 \mathrm{U}$ CubeSat using body-mounted highefficiency triple-junction solar cells is typically less than $10 \mathrm{~W}$ [13]. One technical solution to satisfy the increasing in-orbit power demand is adopting a deployable solar panel that encompasses the expanded surface areas for solar cell 
installation as well as optimizing the orientation or articulation of panels using a solar array drive assembly (SADA) in the Sun's direction. However, the launch vibration environments [14] impose dynamic stresses on the deployable appendages, and the excessive dynamic deflection of the solar panel may cause stress or cracking on solar cells mounted on the panel through the bounded junction. In general, solar cells in a panel are wired in a series connection to achieve a higher voltage when one of the cells fails to generate power, thereby causing electrical energy loss from the solar panel. Hence, minimization of the dynamic deflection of a solar panel under a severe launch environment is an important aspect for a successful CubeSat mission.

In order to overcome this issue, several mechanical design strategies, such as increasing the eigenfrequency of the solar panel by implementing stiffeners made of aluminum or fiberglass-laminate $[15,16]$, using carbon fiber-reinforced plastic (CFRP) and honeycomb panels, or employing multiple holding and release mechanisms (HRMs) to provide additional mechanical fixation points have been practiced by considering the design specification and mission requirements. However, the implementation of the additional stiffener approach involves a tradeoff between the panel's stiffness and weight, which might be a disadvantage for the CubeSat as it has a restraint mass budget. Additionally, the increased mass inevitably increases the panel excitation under a launch load owing to the increased acceleration; this may result in an undesirable burden on the HRM, based on the burn wire triggering release mechanism. The CFRP and honeycomb panels are relatively lightweight and exhibit high rigidity; however, they are expensive and thick in size, which has made them less practical for the CubeSat platform owing to the internal restraint edge gap on the poly-picosatellite orbital deployer (P-POD) for solar panel accommodation [17, 18] and development cost limitations. Recently, as an alternative solution to the aforementioned issues, multiple HRMs have been applied to provide additional mechanical fixation points on a $6 \mathrm{U}$ or larger sized solar panels to minimize dynamic deflections [19]. However, this can increase the system complexity, development cost, and reduce the available area for solar cell accommodation. Furthermore, the MMA design LLC [20] has recently proposed various configurations of mass-effective multiarray-based deployable solar panels, where an additional launch restraint mechanism is implemented in conjunction with a wire cutting release mechanism to reduce panel dynamic deflection and mitigate stress on the HRM under launch environment. However, the implementation of an additional launch restraint device creates system complexity.

Another technical challenge related to deployable solar panels is the necessity for reliable HRMs to provide adequate strength and stiffness for survival in launch environments and release functions to allow deployment in orbit. Several mechanisms have been developed and used in CubeSat applications [21-23]. Among them, a burn wire triggering release method is typically used in deployable solar panels owing to its simplicity and low cost. However, as the size of CubeSat's solar panel becoming larger for advanced missions, these mechanisms should be improved because of their limited loading capability, lack of mechanical constraints along the in-plane direction of the solar panel, and difficulty in wire knotting on the flat surface.

In the present study, to overcome the aforementioned drawbacks of conventional deployable solar panels, we herein propose a novel high-damping deployable solar panel module combined with a pogo pin-based burn wire cutting HRM. A printed circuit board- (PCB-) based solar panel that employs multilayered stiffeners interlaminated with viscoelastic acrylic tapes was manufactured based on the results of a previous study [24], in which the basic dynamic characteristics of the panel with respect to the number of stiffener attachment conditions were demonstrated through freevibration tests. An important advantage of the proposed solar panel is that the dynamic deflection and stresses in the panel under launch vibration loads can be effectively minimized owing to the superior damping characteristic achieved using the multilayered stiffener with viscoelastic acrylic tapes. In order to employ a highly damped deployable solar panel in a real-time CubeSat mission, the solar panel should be qualified under severe launch and in-orbit environments tests at the module level. The solar panel's holding and releasing action is achieved using a new version of the spring-loaded pogo pin mechanism. This mechanism can overcome the aforementioned limitations of the conventional burn wire triggering release mechanisms through increased loading capability, multiplane constraints, and reliable release. The feasibility and effectiveness of pogo pins in the HRM have been investigated by Park et al. [25] and Bhattarai et al. [26], although the proposed mechanism has many advantages, including a compact size, a simpler electrical circuit, and handling simplicity during wire knotting process. The functionality of the newly proposed mechanism was tested via release function tests of the solar panel. In addition, to validate the effectiveness of the design for ensuring the structural safety of solar cells under a launch vibration environment, sine and random vibration tests were performed at the qualification level. Additionally, a thermal vacuum (TV) test was conducted to validate the structural safety of the solar panel and functionality of the pogo pin-based mechanism in a space-simulated TV environment. Subsequent to all the qualification tests addressed above, an optical microphotograph test on the solar panel side edge was conducted for visual inspections. These test and inspection results demonstrate that the deployable solar panel module proposed in this study is effective for ensuring the structural safety of solar cells under launch environments and the stable release action of the solar panel in an in-orbit environment.

\section{High-Damping Deployable Solar Panel Module Combined with the Pogo Pin- Based HRM}

2.1. Design Description. Figure 1 shows the stowed and deployed configuration of the high-damping deployable solar panel module proposed in this study for the application of $3 \mathrm{U}$ CubeSat, which is mainly composed of a viscoelastic multilayered stiffener-based solar panel, a pogo pin-based HRM, 


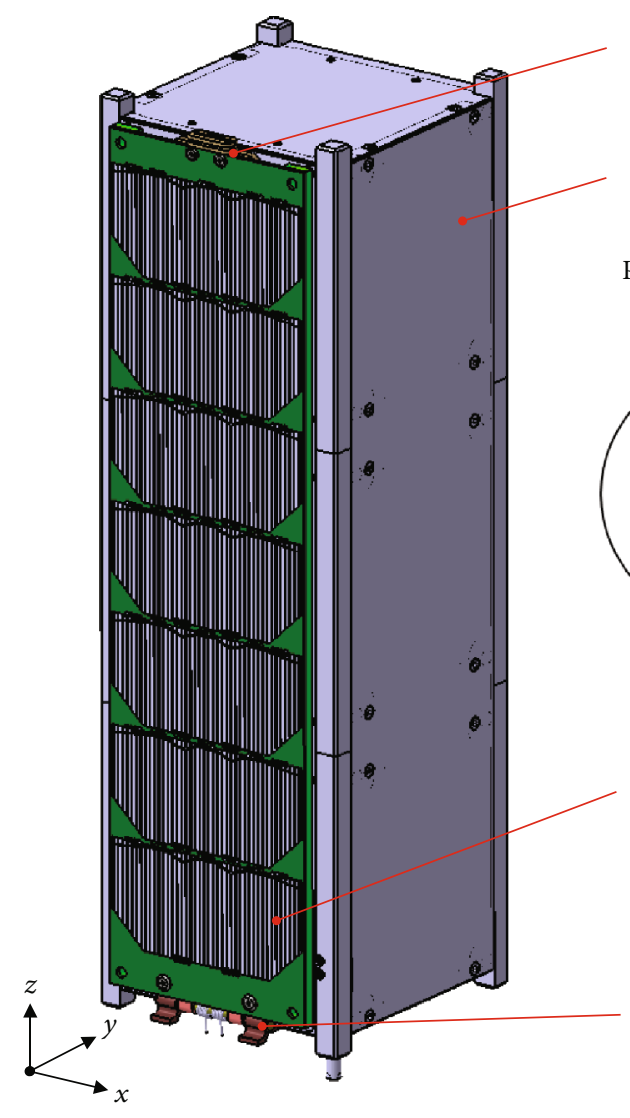

(a)

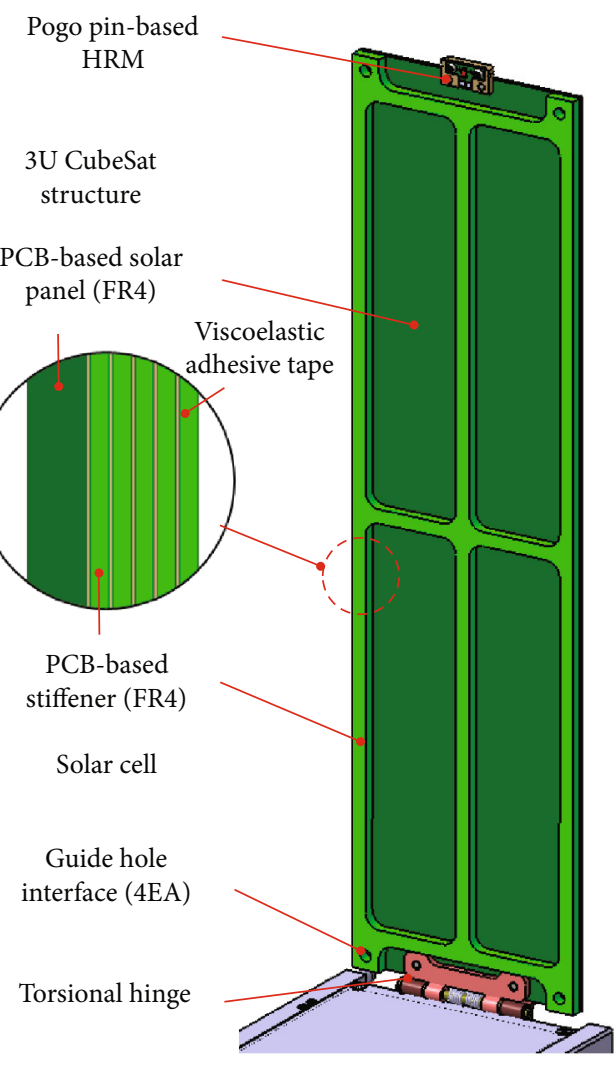

(b)

FIGURE 1: Configuration of the highly-damped deployable solar panel module with pogo pin-based HRM: (a) stowed and (b) deployed.

TABLE 1: Specification of the $3 \mathrm{M}^{\mathrm{TM}} 966$ adhesive transfer tape [27].

\begin{tabular}{|c|c|c|}
\hline Item & Details & Value \\
\hline \multirow{9}{*}{$\begin{array}{l}3 \mathrm{M}^{\mathrm{TM}} 966 \text { adhesive } \\
\text { transfer tape }\end{array}$} & Manufacturer & $\begin{array}{c}3 \mathrm{M} \\
\text { Company }\end{array}$ \\
\hline & Adhesive material & Acrylic \\
\hline & Color & Transparent \\
\hline & Thickness (mm) & 0.06 \\
\hline & $\begin{array}{l}\text { Thermal conductivity } \\
\left(\text { at } 41^{\circ} \mathrm{C}\right)(\mathrm{W} / \mathrm{m} / \mathrm{K})\end{array}$ & 0.178 \\
\hline & $\begin{array}{l}\text { Coefficient of thermal } \\
\text { expansion }\left(\mathrm{ppm} /{ }^{\circ} \mathrm{C}\right)\end{array}$ & 1.99 \\
\hline & Allowable temperature $\left({ }^{\circ} \mathrm{C}\right)$ & -40 to 232 \\
\hline & $\begin{array}{l}\text { Adhesive strength (to steel) } \\
\text { (N/100 mm) }\end{array}$ & 159 \\
\hline & $\begin{array}{c}\text { Outgassing } \\
(\%, \text { TML/CVCM })\end{array}$ & $0.93 / 0.01$ \\
\hline
\end{tabular}

and a torsional hinge. The solar panel is comprised of a $\mathrm{PCB}$ panel, thin PCB stiffeners, and viscoelastic acrylic tapes. The PCB panel was made of FR4 material with dimensions 320 $\mathrm{mm} \times 82 \mathrm{~mm} \times 1.6 \mathrm{~mm}$; it provided a mechanical interface for the integration of stiffeners and solar cells. Five layers of thin PCB stiffeners, as shown in Figure 1, made of FR4 material with a thickness of $0.5 \mathrm{~mm}$, were attached to the rear surface of the PCB panel using double-sided $3 \mathrm{M}^{\mathrm{TM}} 966$ acrylic
TABLE 2: Mass budget of the demonstration model of the $3 \mathrm{U}$ solar panel module.

\begin{tabular}{lc}
\hline Items & Mass $(\mathrm{g})$ \\
\hline PCB panel & 93 \\
Five layers of the PCB stiffener & 45 \\
Five layers of the adhesive tape & 3 \\
Pogo pin-based HRM & 6 \\
Torsional hinge & 11 \\
Total & 158 \\
\hline
\end{tabular}

tape [27], which is a high-temperature acrylic adhesive with low outgassing properties that satisfy the National Aeronautics \& Space Administration (NASA) low volatility specification criteria of ASTM E596. The detailed specifications of the $3 \mathrm{M}^{\mathrm{TM}} 966$ acrylic tape are presented in Table 1.

The basic principle for ensuring the structural safety of solar cells in a launch environment is reducing the dynamic deflection and stress of the solar panel by attenuating the launch vibration loads through the share deformation characteristics of laminated adhesive tapes. To ensure the symmetrical attachment and uniform bonding strength distribution of the tapes, four guide holes were implemented at the four edge corners of the stiffeners and the PCB panel. The total thickness of the solar panel after the integration of the five layers of stiffener on the PCB panel was $4.5 \mathrm{~mm}$, which allows an additional 


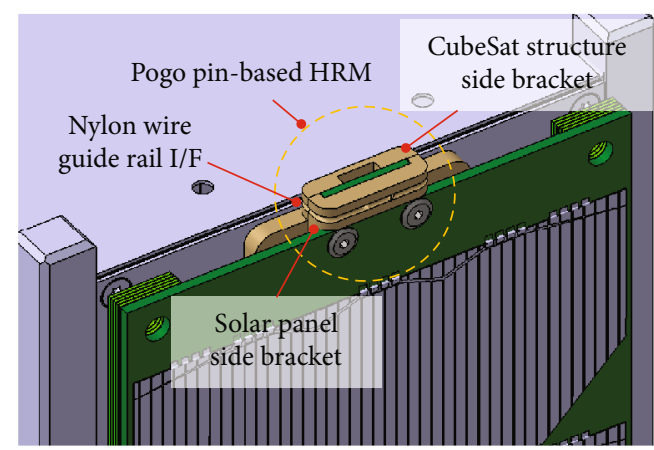

(a)

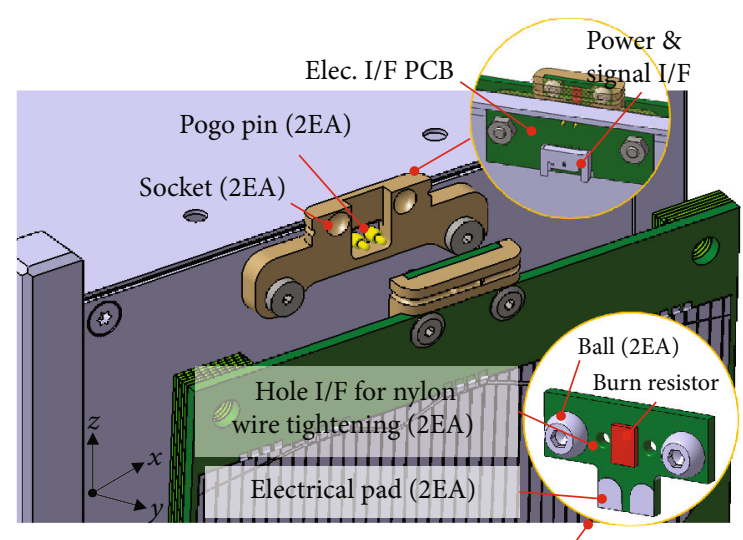

Burn resistor PCB

(b)

FIgUre 2: Close-up views of the pogo pin-based mechanism: (a) fully stowed and (b) partially stowed.

TABLE 3: Basic specifications of the hardware used in the mechanism.

\begin{tabular}{|c|c|c|}
\hline Item & Detail & Value \\
\hline \multirow{7}{*}{ Pogo pin } & Manufacturer & $\begin{array}{c}\text { CFE corporation } \\
\text { Co. }\end{array}$ \\
\hline & $\begin{array}{l}\text { Maximum allowable voltage and } \\
\text { current }(\mathrm{V}, \mathrm{A})\end{array}$ & 12,3 \\
\hline & Contact resistance $(\mathrm{m} \Omega)$ & Max. 50 \\
\hline & $\begin{array}{c}\text { Maximum number of loadings } \\
\text { (cycle) }\end{array}$ & 50,000 \\
\hline & Qualification temperature $\left({ }^{\circ} \mathrm{C}\right)$ & -40 to 85 \\
\hline & $\begin{array}{l}\text { Operation power of the spring- } \\
\text { loaded pin }(\mathrm{N})\end{array}$ & $0.78 \pm 0.16$ \\
\hline & Working stroke $(\mathrm{mm})$ & 1 \\
\hline \multirow{4}{*}{$\begin{array}{l}\text { Nylon } \\
\text { wire }\end{array}$} & Manufacturer & Berkley \\
\hline & Material & Fluorocarbon \\
\hline & Diameter (mm) & 0.2 \\
\hline & Max. allowable force $(\mathrm{N})$ & 57.88 \\
\hline \multirow{6}{*}{$\begin{array}{l}\text { Burn } \\
\text { resistor }\end{array}$} & Manufacturer & $\begin{array}{l}\text { Walsin } \\
\text { technology Co. }\end{array}$ \\
\hline & Package & SMD type \\
\hline & Package size code & 3216 \\
\hline & Electrical resistance (ohm) & 4.7 \\
\hline & Resistance tolerance (\%) & \pm 1 \\
\hline & Max. power dissipation (W) & 0.25 \\
\hline
\end{tabular}

margin of $5.5 \mathrm{~mm}$ in lateral edge gap in the P-POD for a dynamic clearance [18]. Table 2 shows the mass budget of the demonstrated model of $3 \mathrm{U}$ CubeSat's solar panel module. This constraint layer damping with viscoelastic acrylic tapes strategy could be useful for the structural protection of solar cells in a lightweight and compact volume without reducing the solar cell accommodation area because fastener interfaces are not required to attach stiffeners on the panel, which cannot be achieved with materials used in the current state-of-the-art deployable solar panels.
2.2. Holding and Release Mechanism. Figures 2(a) and 2(b) show the close-up view of the newly proposed pogo pinbased HRM with a fully and partially stowed solar panel, respectively. The mechanism is mainly composed of pogo pins, an electrical interface $\mathrm{PCB}$, a burn resistor, a burn resistor $\mathrm{PCB}$, brackets, and a nylon wire. The spring-loaded pogo pin is an electromechanical connecting hardware that is typically used in the field of electronics for the implementation of a temporary connection between two electrical circuits. The pogo pin consists of a plunger, a barrel, and a spring. The advantages of using a pogo pin connector in an electrical device are space-saving connection, relatively low sliding friction, and easy connection and disconnection of the electrical circuit. The key design driver for using pogo pins (MP210-2160-B02 100A, CFE Corporation Co.) [28] is to create a secure electromechanical contact between the electrical interface PCB and burn resistor PCB implemented at the CubeSat edge and solar panel, respectively, with the intention of providing electrical power to the burn resistor during mechanism activation. The mechanical constraint along the out-of-plane direction of the solar panel is achieved by tightening the nylon wire on the guide rail interface of the CubeSat structure side bracket and solar panel side bracket. These brackets allow a mechanical interface to the burn resistor PCB and the ball and socket. The screwed bolts used to fasten the burn resistor PCB in the solar panel side bracket has a ball-shaped overhead tip that acts as a ball, and the rounding notching on the CubeSat structure side bracket is used for the socket. The in-plane direction constraints at the panel are achieved through a combination of the ball and socket joints, where the socket restricts the movement of the ball in a certain nominal gap, thereby preventing unintentional burden at the tightened nylon wire during the launch vibration environment. In addition, it also acts as a mechanical limiter to avoid undesirable panel strikes on the pogo pins beyond the range of $1 \mathrm{~mm}$ working stroke of the spring-loaded pin. To release the holding mechanical constraint of the solar panel, a surface-mounted burn resistor (3216 SMD type, Walsin Technology Co.) [29] is used as an actuator that releases the solar panel by cutting the nylon wire tightened along 


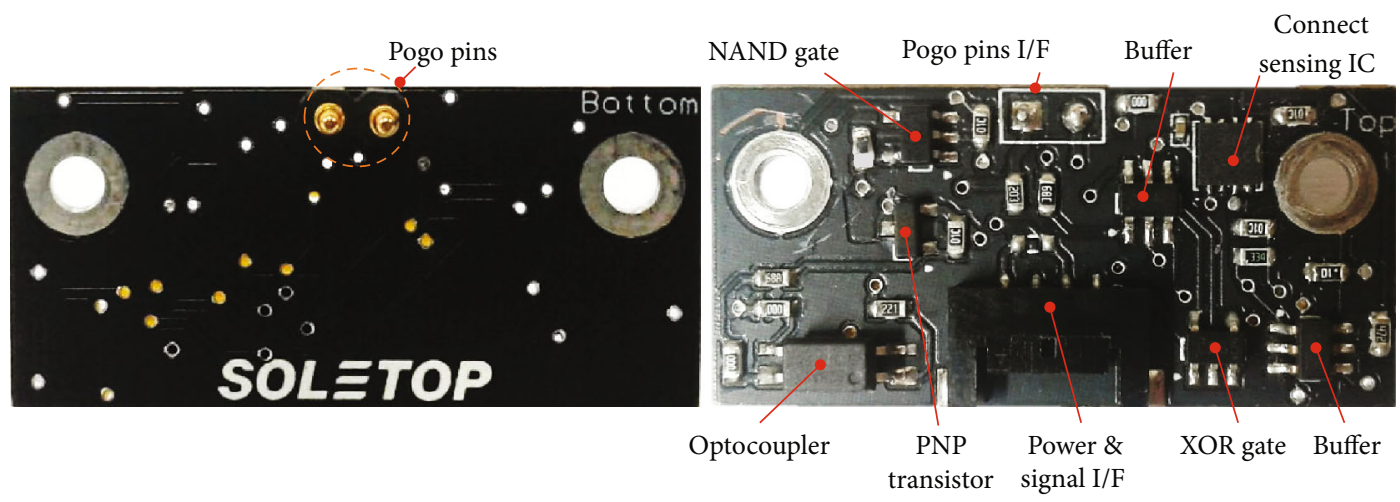

(a)

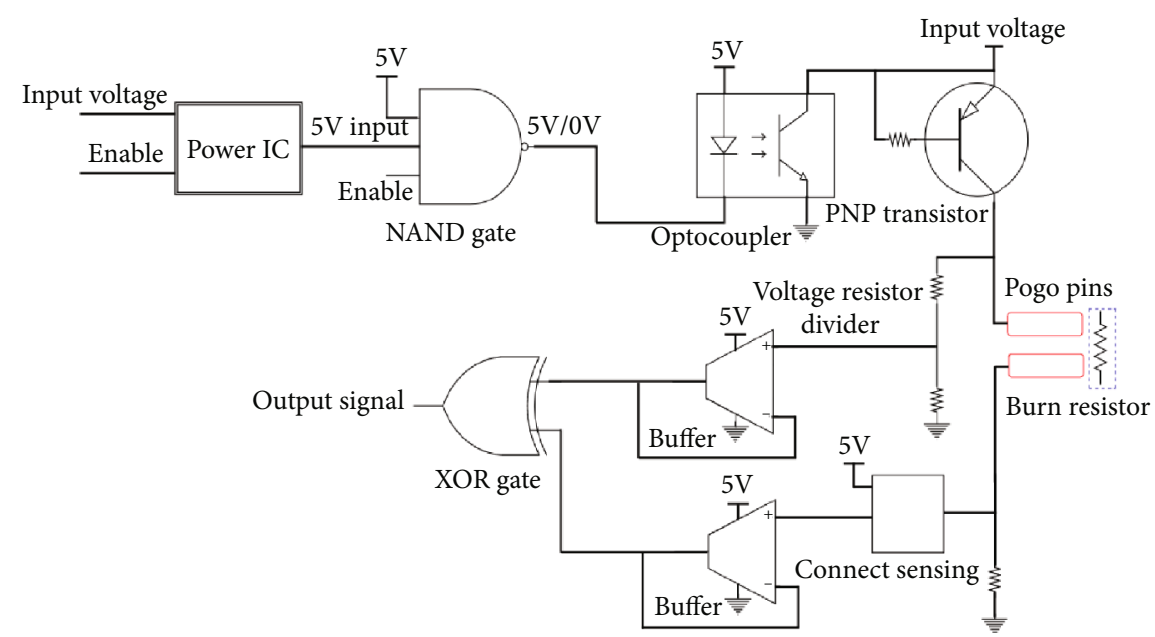

(b)

FIGURE 3: Electrical system of the pogo pin-based mechanism: (a) from and rear views of the electrical interface PCB (dimensions: 34 mm $\times 16 \mathrm{~mm} \times 1 \mathrm{~mm}$ ) and (b) schematic block diagram.

the guide rail interface of brackets once the mechanism is triggered via the power supply in the circuit. The compression force of the spring-loaded pogo pin, $0.78 \pm 0.16 \mathrm{~N}$, initiates the panel deployment instantly after the burn resistor thermally cuts the nylon wire, which can also quickly or easily interrupt the circuit path to the burn resistor. Subsequently, the passive torsional force of the torsional hinge deploys the solar panel at its intended position. Table 3 summarizes the basic specifications of the hardware used in the mechanism.

2.3. Electrical System. Figures 3(a) and 3(b) show the electrical interface PCB and the schematic electrical block diagram of the pogo pin-based HRM electrical system, respectively. The electrical system is mainly composed of a power IC, a NAND gate, an optocoupler, and a PNP transistor for providing power to the burn resistor, and two buffer ICs with an XOR gate to determine the solar panel deployment signal. The input voltage to the burn resistor for mechanism activation is set to $8 \mathrm{~V}$, while $5 \mathrm{~V}$ is supplied to the electrical components, which can be adequately provided by the CubeSat power system using commercial Li-ion batteries in the initial orbital ejection phase. An optocoupler (PC817) [30] was used to prevent electrical malfunction in the circuits at a high volt- age. In the optocoupler, electrical signals between two isolated circuits are transferred through light. The power cutoff function after panel deployment was achieved through the electrical circuit shown in the block diagram; it did not require a microcontroller unit (MCU), thereby reducing the cost of the mechanism. In this study, an XOR gate (SN74LVC1G86DBVR) [31] was used in the circuit to utilize the function of pogo pins as a deployment status switch that provides a telemetry of " 1 " or " 0 " according to current flow status through a burn resistor, where " 1 " represents the fraction of input voltage to the circuit at voltage resistor divider. The electrical interface PCB was compact; it measured 34 $\mathrm{mm} \times 16 \mathrm{~mm}$ and was implemented to the back of the CubeSat structure side bracket through bolt fastening. This makes it possible to implement the function of power, switch, and mechanical interface for pogo pins integration into the mechanism. Hence, the mechanism proposed in this study is simple, inexpensive, and compatible with the P-POD rail without interfering with the $z$-axis of the CubeSat structure.

2.4. Nylon Wire Tightening Procedure. Figure 4 demonstrates the nylon wire tightening process along the guide rail interface of the brackets for the mechanical constraints in the panel's out-of-plane direction. The nylon wire (Berkley, 

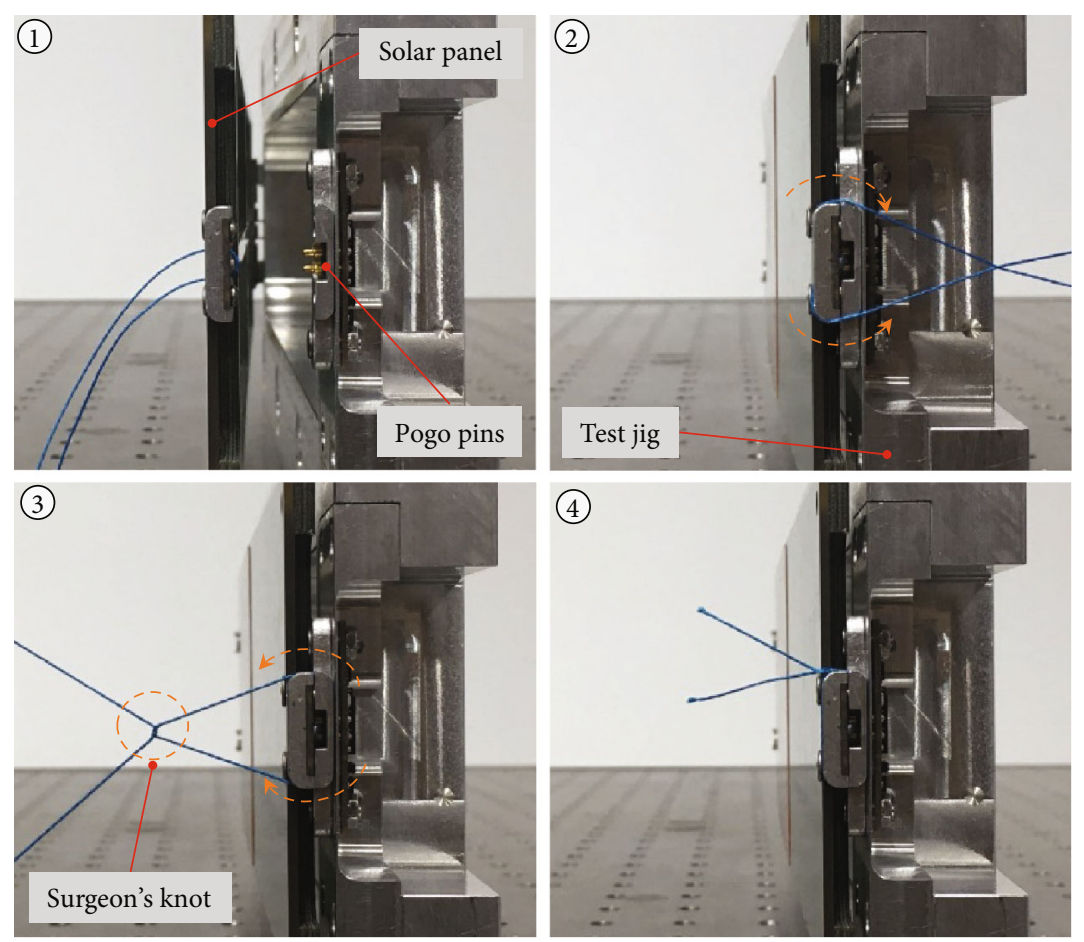

FIGURE 4: Nylon wire tightening process for holding constraint at the panel.

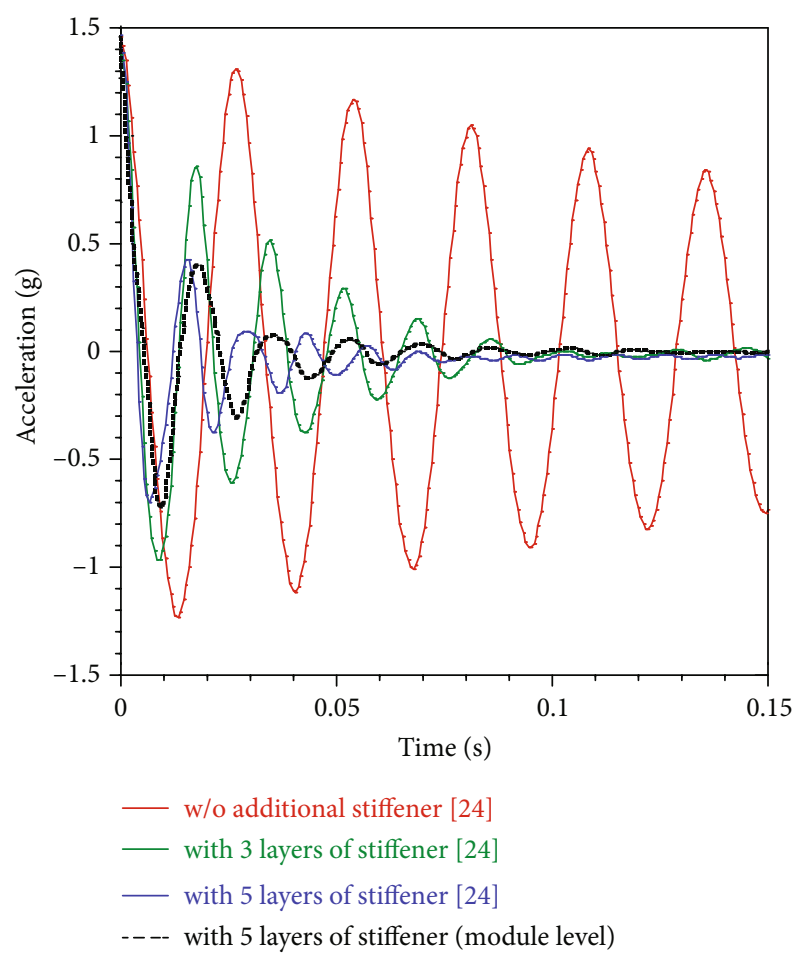

FIGURE 5: Time histories of the free-vibration tests of solar panels with various numbers of stiffeners.

Nanofil) [32] made of fluorocarbon material, with a diameter of $0.2 \mathrm{~mm}$, was wound around the guide rail interface of the brackets and had a maximum allowable strength of $57.88 \mathrm{~N}$. Hence, the nylon wire has an adequate strength to stow the panel during launch environment and possessed space heritage [25]. However, as the size of a solar panel is larger for advanced missions, the loading capability can be increased by increasing the number of wire windings. A surgeon's knot was performed out for the final knotting of the wire at the bracket corner; it enabled steady and tight tension on the knot of the tightened wire. The nylon wire guide rail interface notching on the brackets prevents wire misalignment during the launch vibration period. Moreover, the edge fillet on the four corners of the brackets distributes the corner stress of the tightened wire, which is an important mechanical aspect for the structural safety of the tightened nylon wire. The effectiveness of the wire tightening method was validated through solar panel separation tests, which will be described in more detail in the next section. This tightening method provides an increased holding constraint force as the nylon wire is tightened around the rectangular brackets with fillet edges; furthermore, this method enables a reliable cutting of the nylon wire upon the activation of the mechanism. Thus, the handling of the nylon wire during the wire tightening process is considerably simpler and more reliable than that of conventional mechanisms in which the nylon wire is tightened on the flat surface of the solar panel.

\subsection{Basic Dynamic Characteristics of the Solar Panel. Figure 5} shows the representative damping characteristics of solar panels according to various numbers of viscoelastic multilayered stiffener attachment conditions, obtained through freevibration tests performed at an ambient room temperature of $25^{\circ} \mathrm{C}$ under the boundary condition that both the hinge and the HRM holes interfaces are rigidly clamped [24]. The damping ratios calculated from the vibration period of solar 


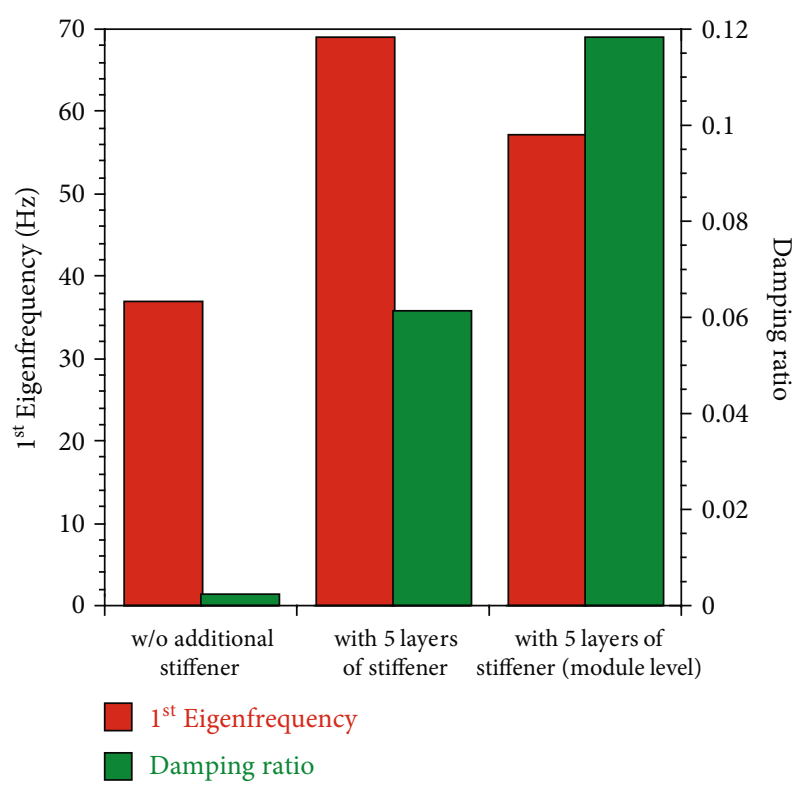

Figure 6: Basic dynamic characteristics of the solar panels according to clamping boundary conditions.

panels with three and five layers of viscoelastic stiffener were 0.019 and 0.061 , respectively, which were higher by factors of 9.5 and 30.5, respectively, than the damping ratio of 0.002 obtained for the solar panel without using additional stiffeners. Furthermore, the $1^{\text {st }}$ eigenfrequency of the solar panel without additional stiffeners and using three and five layers of stiffener were $36.70,63.52$, and $68.81 \mathrm{~Hz}$, respectively. The results demonstrate that the application of the viscoelastic multilayered stiffener enhanced the vibration damping and increased the stiffness of the solar panel as the number of interlaminated layers increased owing to the large shear strain and relatively rough surface roughness between the viscoelastic and constraining layers [33]. Furthermore, in a previous study [24], the dynamic characteristic variation of solar panels under various temperature conditions, ranging from $-20^{\circ} \mathrm{C}$ to $60^{\circ} \mathrm{C}$, was investigated to predict their design effectiveness during in-orbit operation via free-vibration tests. These tests were performed in a thermal chamber with an isothermalization dwell time of $1 \mathrm{~h}$ at specified test temperatures. The aforementioned temperature range encompassed the expected glass-transition region of the $3 \mathrm{M}^{\mathrm{TM}} 966$ acrylic tape, where the mechanical properties of the material instigating from the elastic to the rubbery state. However, the allowable temperature of the tape was $-40^{\circ} \mathrm{C}$ to $232^{\circ} \mathrm{C}$ [27]. The results reveal that the damping ratio and stiffness of the solar panel employing multilayered stiffeners interlaminated with viscoelastic acrylic tapes was relatively higher than that of the solar panel without additional stiffeners throughout the test temperature range. This is because of the cumulative shear strain and the nearly stable adhesive strength accomplished on the multiple thin stiffeners using the high-temperature acrylic adhesive tapes. In the present study, the five viscoelastic multilaminated stiffeners on the panel were determined through the above free-vibration test results, considering the accommodation in the $\mathrm{P}$ -
POD rail interface for dynamic clearance and the total mass of the solar panel module.

To demonstrate the effectiveness of the proposed solar panel for transmitted vibration attenuation at the module level, a free-vibration test was performed at ambient room temperature of $25^{\circ} \mathrm{C}$ in the panel stowed state by considering the hinge and HRM, which correspond to the solar panel launch configuration. The time history of the proposed solar panel's acceleration response is plotted in Figure 5 for comparison with the results obtained in the rigidly mounted condition. Figure 6 summarizes the values of the damping ratio and $1^{\text {st }}$ eigenfrequency of the solar panels based on the clamping boundary conditions. The results reveal that the $1^{\text {st }}$ eigenfrequency of the proposed solar panel was $58.98 \mathrm{~Hz}$, which is $10 \mathrm{~Hz}$ lower than that of the rigidly mounted solar panel employing the same number of stiffeners. This dissimilarity in stiffness was anticipated owing to differences in the solar panel clamping condition. However, the solar panel damping ratio calculated from the logarithmic decrement equation was 0.118 , which is higher by a factor of 1.93 than that of the rigidly mounted solar panel interlaminated with the same number of viscoelastic layers. This is because additional damping occurred at the mechanical tolerance gap of the hinge in the form of friction, and the nylon wire knot of the HRM brackets served as a spring element. Therefore, the damping ratio at the center of the panel increased slightly, as the transmitted vibration load attenuated additionally in the solar panel mounting interfaces. These test results confirm that the proposed solar panel guarantees enhanced dynamic characteristics, such as stiffness and damping performance, in the launch configuration, unlike the typical solar panel without additional stiffeners.

\section{Experimental Validation of Solar Panel Module}

3.1. Release Function Test. To validate the stable release function of the proposed pogo pin-based deployment mechanism of the solar panel, release function tests were performed at ambient room temperature using the experimental test setup shown in Figure 7 . In order to minimize the gravitational effect during panel deployment, the solar panel module was installed horizontally such that the hinge's rotational axis was perpendicular to the test table. The HRM, as shown in Figure 2, was connected to a power supply for mechanism activation and to a data acquisition (DAQ) system for monitoring the input voltage and solar panel separation status signal during the test. The input voltage to the burn resistor for mechanism activation was set to $8 \mathrm{~V}$, which can be sufficiently provided by the $3 \mathrm{U}$ CubeSat power system using commercial Li-ion batteries at an initial orbital ejection phase. In addition, an accelerometer was attached to the center of the solar panel to measure the panel acceleration during deployment.

Figure 8 shows the time history of the input voltage, separation signal, and acceleration of the solar panel measured during the test. The release status data were obtained using the XOR gate of the electrical circuit shown in the electrical block diagram (in Figure 3) through the DAQ channel; these 


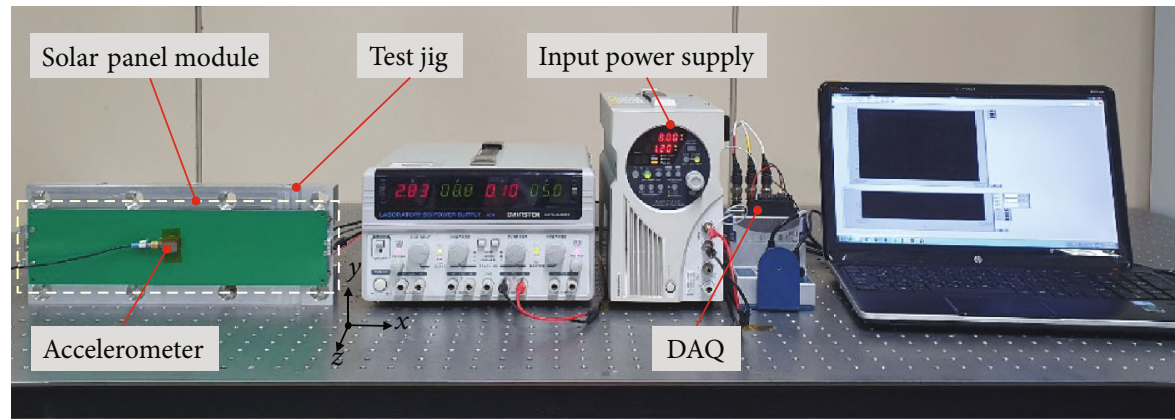

FIGURE 7: Release function test setup of the demonstration model of the $3 \mathrm{U}$ solar panel.

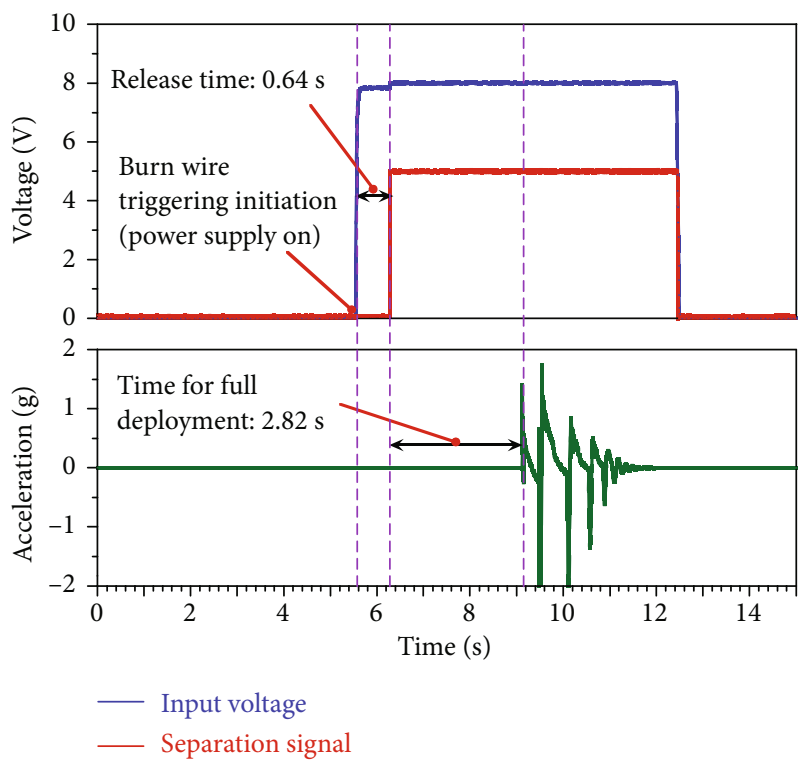

Figure 8: Time histories of the input voltage, separation signal, and acceleration response obtained from release test of the solar panel.

data indicate that the solar panel was released within $0.64 \mathrm{~s}$ from the initiation of burn wire triggering. In addition, the acceleration response of the solar panel demonstrates that the full deployment of the panel took $2.82 \mathrm{~s}$ from the completion of the release action. This test result indicates that the proposed mechanism functioned well, and the solar panel deployment status was determined in accordance with the temporal electrical connection accomplished by the pogo pins as intended in the design.

The several numbers of release function tests of the mechanism were required throughout the CubeSat development and testing phase. According to ECSS-E-ST-33-01C [34], for a minimum of 10 normal on-ground release tests, including run-in, acceptance testing, and one in-orbit release, the mechanism should be verified by performing at least 20 repeatability tests at ambient room temperature. Thus, to validate the repeatability of the proposed mechanism, repetitive release function tests were performed with the same test configuration, as shown in Figure 7. The results plotted in Figure 9 indicate that the mechanism was operating well with no failure on the burn resistor during 20 repetitive activations of the mechanism; however, the release time varied slightly owing to the

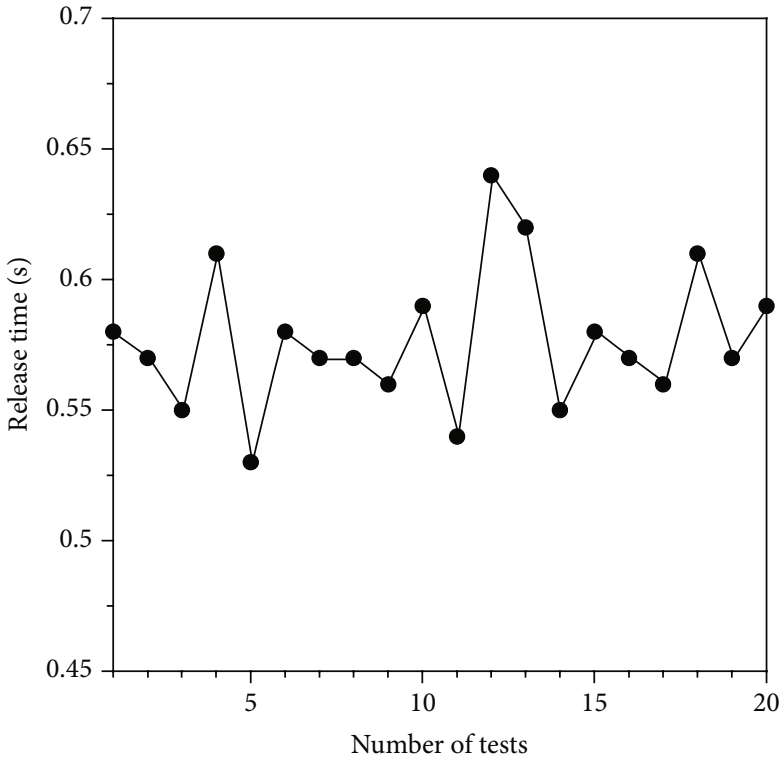

FIGURE 9: Release times of the solar panel during repetitive release function tests of the mechanism.

workmanship to apply tension on the nylon wire knot during the tightening process. The average release time of the mechanism during the 20 times of repetitive activation was $0.58 \mathrm{~s}$. These results indicate that the mechanism assured sufficient repeatability for use in CubeSat applications.

3.2. Launch Vibration Test. To verify the structural safety and damping performance of the proposed design of the solar panel module in a launch environment, launch vibration tests, such as sine and random vibration tests, were performed under the qualification level of the launch load specified in Table 4. The main objective of these tests was to verify the design effectiveness of the highly damped deployable solar panel module with a pogo pin-based burn wire cutting HRM to ensure the structural safety of the solar cells in the launch vibration loads.

Figure 10 shows an example of a launch vibration test configuration of the demonstration model of the solar panel module on the electrodynamic vibration shaker (J260/SA7M, IMV Corp.) along with the $z$-axis excitation, which is the most critical axis as it induces the largest dynamic deflection of the solar panel. Accelerometers were attached to the test jig and shaker slip table to monitor the input vibration loads. The output 
TABLE 4: Summary of the qualification-level launch vibration test specifications.

(a)

\begin{tabular}{|c|c|c|c|}
\hline \multicolumn{4}{|c|}{ Sinusoidal vibration test [35] } \\
\hline Level & $\begin{array}{c}\text { Frequency } \\
(\mathrm{Hz})\end{array}$ & $\begin{array}{l}\text { Amplitude } \\
\text { (g) }\end{array}$ & $\begin{array}{c}\text { Sweep rate } \\
\text { (oct } / \mathrm{min} \text { ) }\end{array}$ \\
\hline \multirow{3}{*}{$\begin{array}{l}0 \mathrm{~dB} \text { (full } \\
\text { level) }\end{array}$} & 5 & 1.3 & \multirow{3}{*}{2} \\
\hline & 8 & 2.5 & \\
\hline & 100 & 2.5 & \\
\hline
\end{tabular}

(b)

\begin{tabular}{lcccc}
\hline \multicolumn{5}{c}{ Random vibration test [36] } \\
Level & $\begin{array}{c}\text { Frequency } \\
(\mathrm{Hz})\end{array}$ & $\begin{array}{c}\text { Amplitude } \\
\left(\mathrm{g}^{2} / \mathrm{Hz}\right)\end{array}$ & $\begin{array}{c}\text { Test } \\
\text { duration } \\
(\mathrm{s})\end{array}$ & $\begin{array}{c}\text { RMS } \\
\text { acceleration } \\
\left(\mathrm{G}_{\mathrm{rms}}\right)\end{array}$ \\
\hline & 20 & 0.026 & & \\
$0 \mathrm{~dB}$ (full & 50 & 0.16 & 120 & 14.10 \\
level) & 800 & 0.16 & & \\
& 2000 & 0.026 & & \\
\hline
\end{tabular}

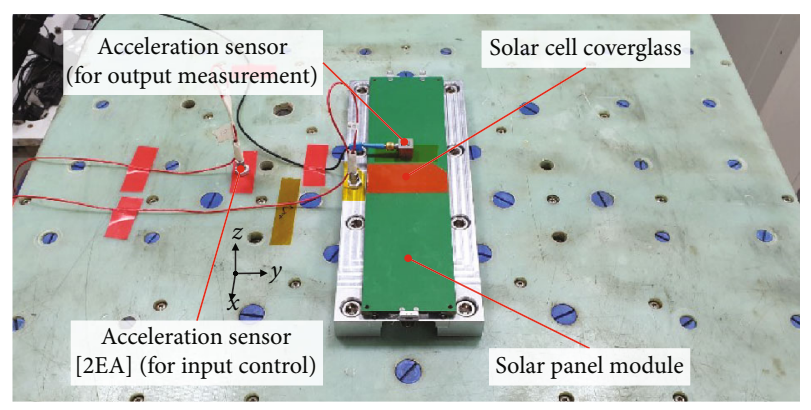

Figure 10: Launch vibration test setup configuration of the demonstration model of the $3 \mathrm{U}$ solar panel module.

acceleration responses of the solar panel were measured using an accelerometer attached near the center of the solar panel. The test was performed at an ambient room temperature of $20^{\circ} \mathrm{C}$. The structural safety of the solar panel module was validated by comparing the variation in the $1^{\text {st }}$ eigenfrequencies of the panel, which were obtained through low-level sine sweep (LLSS) tests performed before and after each vibration test. In order to judge the structural safety of the specimen under the launch load, the $1^{\text {st }}$ eigenfrequency variation in the LLSS should be less than 5\%. Furthermore, a solar cell coverglass was attached to the center of the solar panel using a room-temperature vulcanizing (RTV) silicone adhesive to assess the structural safety of the solar cells. The solar cell attached at that location was vulnerable to fracture owing to panel deflection under a severe launch environment. The survivability of the coverglass was checked through visual inspections of cracks before and after each vibration test. The color of the adhesive was intentionally selected as red for the easy identification of cracks in visual inspections. After completing all the vibration tests, the

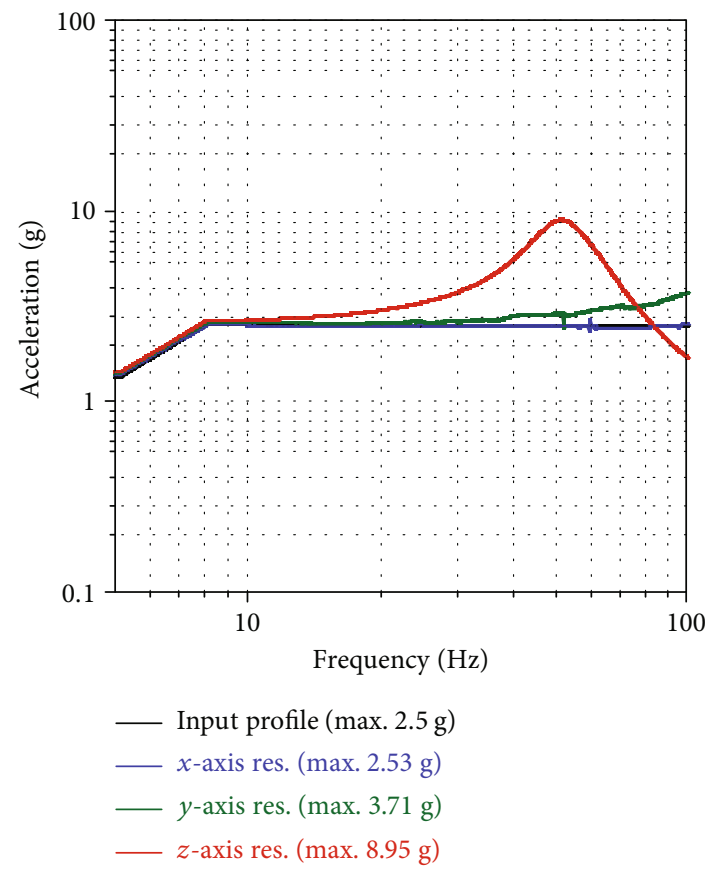

FIgURE 11: Sinusoidal vibration test results of solar panel's corresponding axis in the $x$-, $y$-, and $z$-axis excitations.

release function test was performed on the solar panel to evaluate the reliability of the mechanism.

Figure 11 shows the sine vibration test results of the solar panel module along the $x$-, $y$-, and $z$-axis excitations. In the figure, only the corresponding axis vibration responses of the solar panel with the excitation axis are presented, as the corresponding axis has a larger dynamic response than the other axis of the panel. In the sine vibration tests, the qualification-level input loads specified in Table 4 were applied to the solar panel along each axis; however, the $z$-axis was the most critical axis because it induced the largest dynamic deflection of the solar panel. With respect to the maximum $2.5 \mathrm{~g}$ sine vibration input load in each axis, the maximum acceleration responses of the corresponding $x$-, $y$-, and $z$-axes with the excitation axes within the input frequency range were $2.53,3.71$, and $8.95 \mathrm{~g}$, respectively. The solar panel's maximum resonance response of $8.95 \mathrm{~g}$ was observed at $51.59 \mathrm{~Hz}$ on the $z$-axis during the same axis excitation of the panel. For the same input vibration load, the maximum acceleration response of a typical $3 \mathrm{U}$ solar panel without employing additional stiffeners in the $z$-axis excitation was $43.72 \mathrm{~g}$, which was observed at a frequency of $47.60 \mathrm{~Hz}$ [24]. The acceleration response of the proposed solar panel reduced substantially, by a factor of 4.88 , compared with that of the typical solar panel owing to the resistive shear deformation characteristic achieved using the laminated adhesive tapes; however, the $1^{\text {st }}$ eigenfrequency was lower than the expected value because of the torsional hinge backlash. Figure 12 shows the random vibration test results of the solar panel along each excitation axis with respect to the input level of $14.1 \mathrm{G}_{\mathrm{rms}}$. The corresponding axis $\mathrm{G}_{\mathrm{rms}}$ values of the solar panel along the $x^{-}, y_{\text {-, }}$ and $z$-axis excitations, calculated from power spectral density (PSD) 


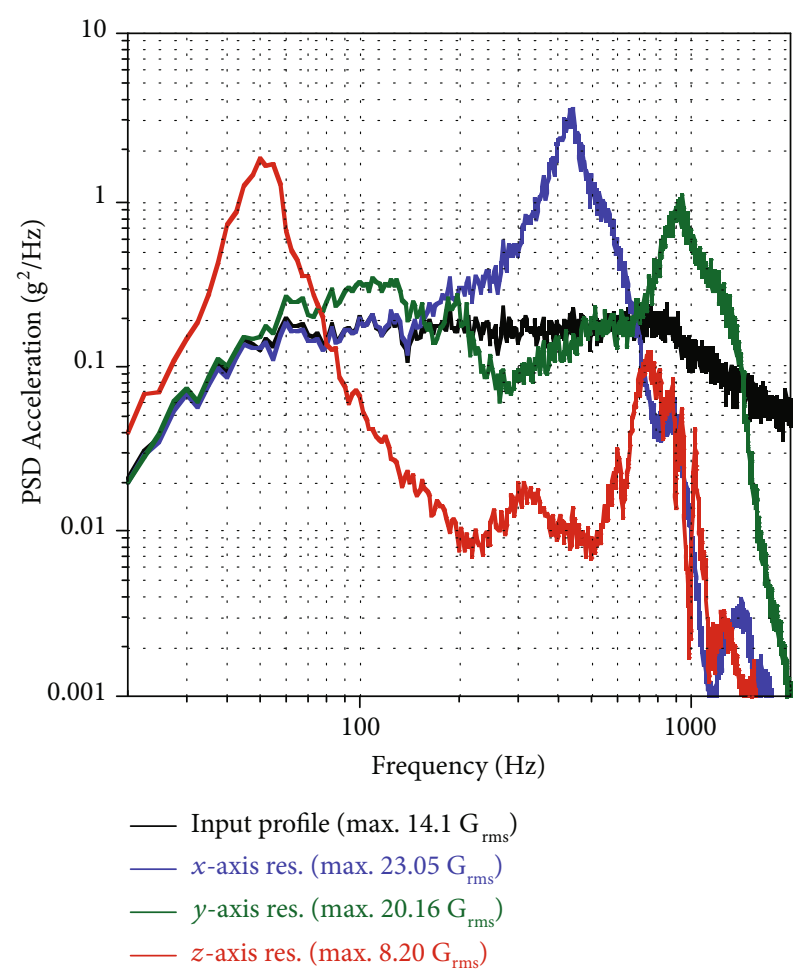

FIGURE 12: Random vibration test results of solar panel's corresponding axis in the $x$-, $y$-, and $z$-axis excitations.

TABLE 5: LLSS test results of the solar panels before and after full level vibration tests.

\begin{tabular}{lcccc}
\hline Test & Axis & Status & $\begin{array}{c}1^{\text {st }} \text { eigenfrequency } \\
(\mathrm{Hz})\end{array}$ & $\begin{array}{c}\text { Difference } \\
(\%)\end{array}$ \\
\hline \multirow{4}{*}{ Sine vibration } & $x$ & Before & 471.58 & 0.45 \\
& & After & 473.71 & \\
& & Before & 111.17 & 3.20 \\
& & After & 107.72 & \\
& $z$ & Before & 54.83 & 0.46 \\
& & After & 54.58 & 0.45 \\
Random & $x$ & Before & 471.58 & \\
vibration & $y$ & After & 473.71 & 0.91 \\
& & Before & 106.28 & 2.31 \\
& $z$ & Before & 105.32 & 55.33 \\
\hline
\end{tabular}

acceleration profiles, were 23.05, 20.16, and 8.20, respectively. The $\mathrm{G}_{\mathrm{rms}}$ of the solar panel in the $z$-axis was lower by a factor of 1.71 than that of the input level.

Table 5 summarizes the $1^{\text {st }}$ eigenfrequencies of the solar panel in each axis obtained through the LLSS tests performed before and after each vibration test. The tabulated result shows that the $1^{\text {st }}$ eigenfrequency shift was within $3.20 \%$ throughout the test sequences of the panel, which was within the $5 \%$ criterion. In addition, after the launch vibration tests have been completed, the solar panel was visually inspected,

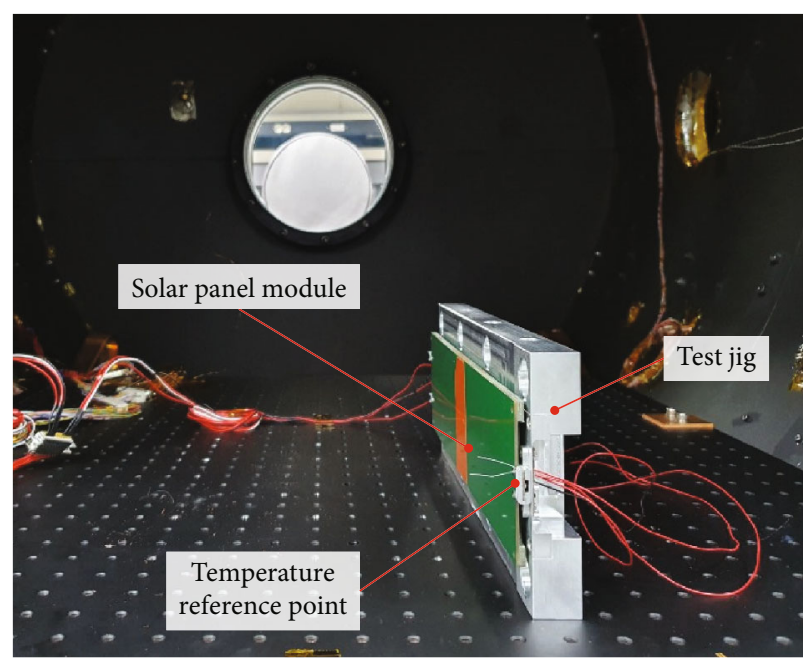

FigURE 13: TV test setup configuration of the solar panel module.

and no crack, dissociation, or plastic deformation was observed on the laminated stiffeners and solar cell coverglass. These tests and inspection results indicate that the structural safety of the proposed solar panel module was successfully validated in the qualification-level launch environment tests.

3.3. Thermal Vacuum Test. Figure 13 shows the TV test setup configuration of the solar panel module in a $\phi 1 \mathrm{~m}$ TV chamber to validate the structural safety of the solar panel and the functionality of the pogo pin-based mechanism under a space-simulated TV environment. Thermocouples were attached to the solar panel and mechanism to measure the temperature of the specimen during the test. A thermocouple mounted on the electrical interface PCB of the HRM was considered as the temperature reference point (TRP) to assess the stabilized target temperature. The solar panel module was exposed to six thermal cycles, with the qualification temperature ranging from $-40^{\circ} \mathrm{C}$ to $60^{\circ} \mathrm{C}$ under a chamber pressure of less than $10^{-5}$ torr. The target temperature of the TRP on the specimen was achieved by controlling the shroud temperature of the TV chamber at a rate of $1^{\circ} \mathrm{C}$ per hour, and the dwell time at the hot and cold plateaus was set to $1 \mathrm{~h}$.

Figure 14 shows the temperature profiles of the solar panel module obtained from the TV cycling tests. The state of health $(\mathrm{SOH})$ check of the solar panel and the mechanism were conducted through the visual inspection at the dwell time of all the hot and cold soak phases. Moreover, the release function test of the mechanism was performed at $-20^{\circ} \mathrm{C}$ in the $3^{\text {rd }}$ cold soak phase, because it was the worst condition for the mechanism activation at the initial orbital ejection period of the satellite. The solar panel was successfully released in 29 s without any anomalies after triggering input voltage was applied; however, the release time was substantially higher than that measured under ambient room conditions owing to the variation in the heating time of the burn resistor for cutting the nylon wire. Additionally, the electrical power dissipation in the input power supply of the wire to the mechanism and the time delay of the deployment relay signal to the DAQ system in an extremely cold environment under 


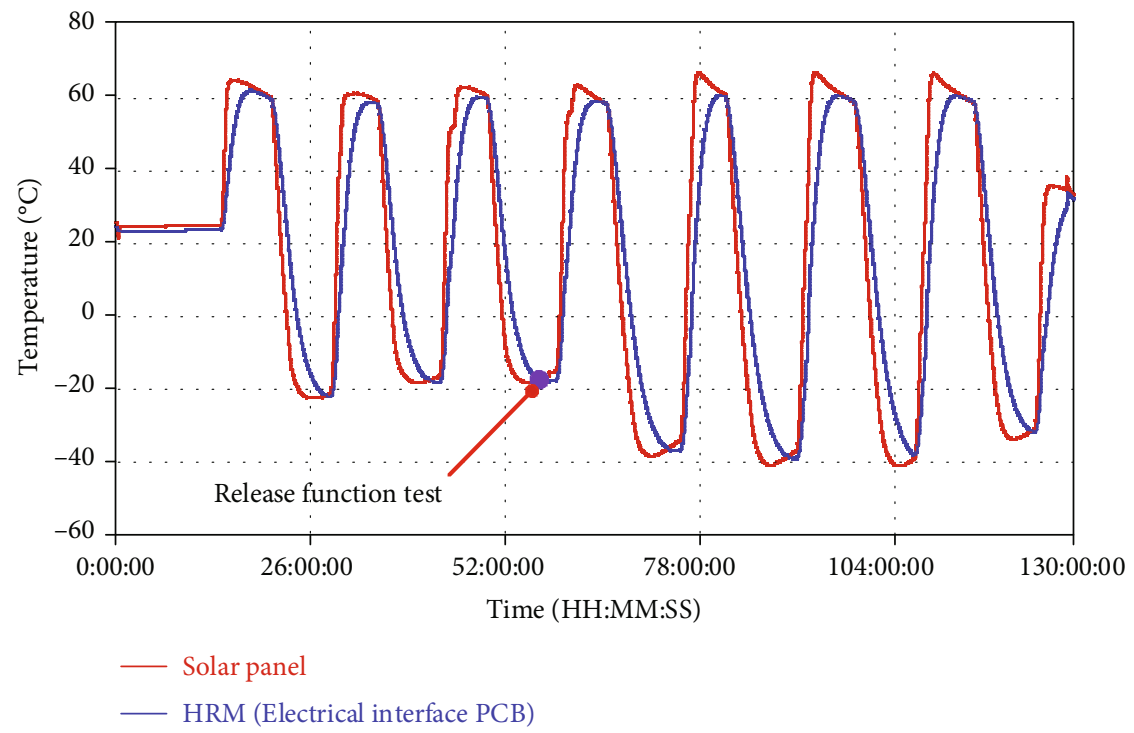

FIgURE 14: Time histories of the temperature profiles of the solar panel module in the TV test.

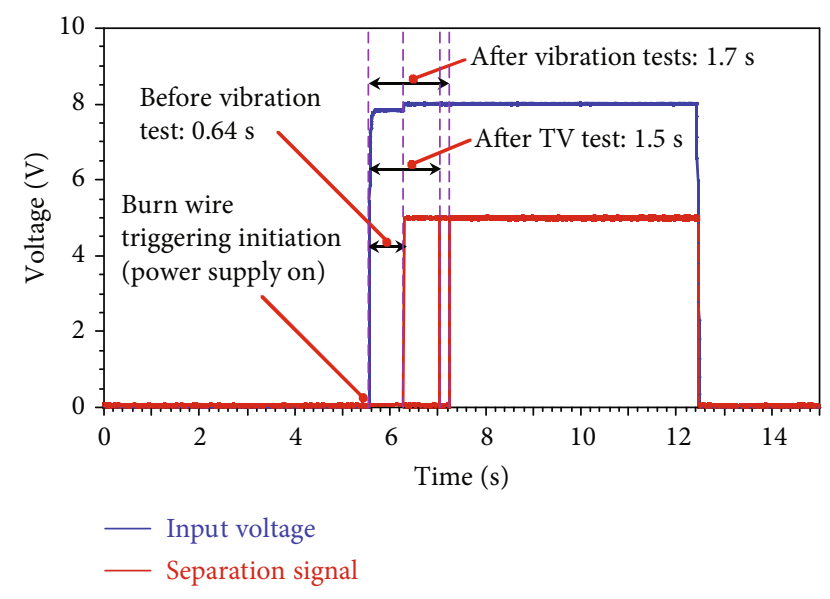

Figure 15: Time histories of release time of the mechanism before and after launch vibration and TV tests.

the TV chamber are also factors in increasing the release time [37]. As the deployment of the solar panel is typically initiated after several minutes to hours of orbital ejection of the CubeSat, the onboard electrical power system of CubeSats has sufficient power to release the solar panel [8, 12]. As shown in the time history of the temperature profile, the first three cycles of the TV test were performed in the temperature range of $-20^{\circ} \mathrm{C}$ to $60^{\circ} \mathrm{C}$. After verifying the release function test of the mechanism, the remaining test cycles were performed in the qualification temperature range of the solar panel.

After the completion of the TV test, the release function test of the mechanism was carried out at ambient room temperature conditions to validate the mechanism's release operation after exposure to the thermal stress in a space simulated TV environment. The corresponding release function test results are presented in Figure 15. The results obtained before and after the vibration tests are plotted in the figure to com- pare the release time. The solar panel was successfully released within $1.5 \mathrm{~s}$ after the burn wire was triggered in the mechanism; however, this value was higher and lower by factors of 2.34 and 1.13 compared with those measured before and after the vibration tests, respectively. In addition, after all the launch vibration and TV environment tests were completed, the solar panel was inspected microscopically. Figures 16(a) and 16(b) show the representative optical microphotographs of the sidereal edge of the solar panel in the pre- and post-TV tests. The inspection results did not indicate any slip, dissociation or plastic deformation in the laminated layers. Furthermore, the visual inspection results shown in Figure 17 indicate no cracks or fractures on the solar cell coverglass after it was exposed in the severe launch vibration and TV environment tests.

\section{Summary of Experimental Validation Test Results}

Table 6 summarizes the release time and structural safety results of the solar panel module for the comparison of the performance at each event. The pass and fail criteria for determining the structural safety of the laminated stiffeners and mounted coverglass were the absence and presence of delamination or cracks, respectively. These qualificationlevel launch vibration and TV environment tests and inspection results validate the structural safety of the proposed solar panel module with the pogo pin-based mechanism.

Furthermore, the relative maximum dynamic displacement at the center of the solar panel was $0.03 \mathrm{~mm}$ during the $z$-direction excitation under a random vibration load, estimated from the three-sigma value of the $G_{\text {rms }}$ response. The maximum dynamic displacement of the proposed solar panel module was reduced significantly by a factor of 46.33 compared with that of the typical $3 \mathrm{U}$ solar panel without a stiffener [24]. This is owing to the higher vibration attenuation resulted from the shear deformation of the viscous layers 


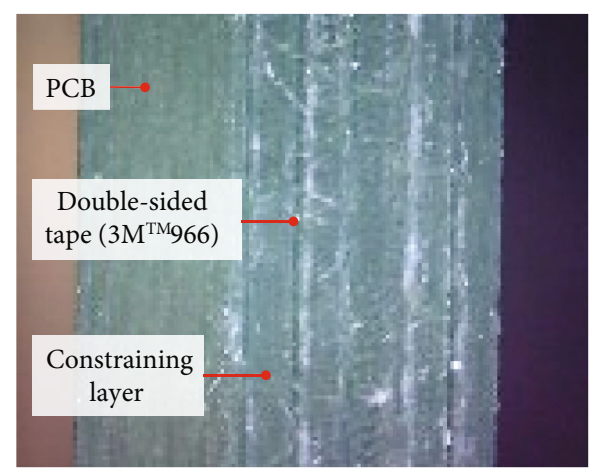

(a)

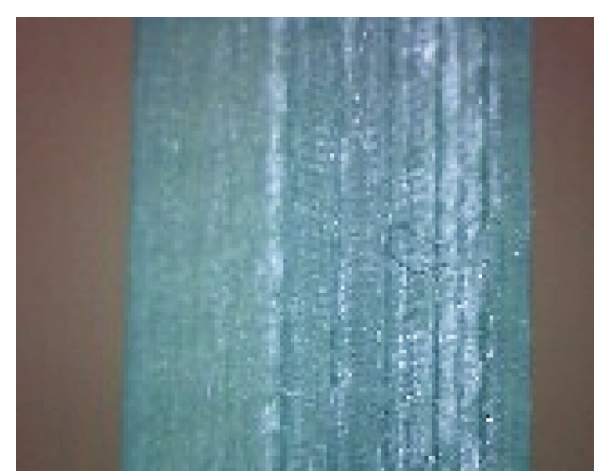

(b)

FIGURE 16: Representative optical microphotographs of the solar panel side edge: (a) before TV environment test and (b) after TV environment test.

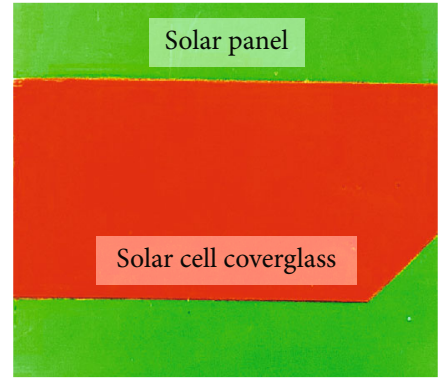

(a)

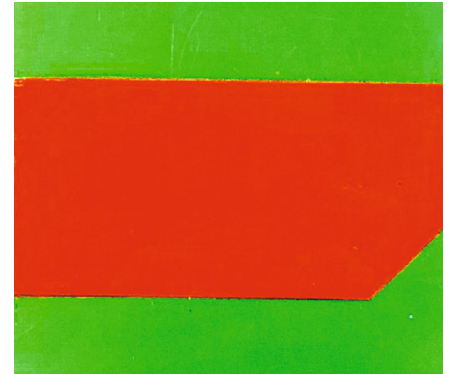

(b)

FIGURE 17: Visual inspection test results of the solar cell coverglass: (a) before TV environment test and (b) after TV environment test.

TABLE 6: Summary of release time and structural safety results of the solar panel module at each event.

\begin{tabular}{|c|c|c|c|c|c|}
\hline \multirow{2}{*}{ Test event } & \multirow{2}{*}{ Input power $(\mathrm{V})$} & \multirow{2}{*}{ Release time (s) } & \multirow{2}{*}{ Solar panel release (pass/fail) } & \multicolumn{2}{|c|}{ Structural safety of the solar panel } \\
\hline & & & & Stiffeners (pass/fail) & Solar cell coverglass (pass/fail) \\
\hline Before vibration & 5 & 0.64 & $\mathrm{P}$ & $\mathrm{P}$ & $\mathrm{P}$ \\
\hline After vibration & 5 & 1.7 & $\mathrm{P}$ & $\mathrm{P}$ & $\mathrm{P}$ \\
\hline During TV test & 5 & 29 & $\mathrm{P}$ & $\mathrm{P}$ & $\mathrm{P}$ \\
\hline After TV test & 5 & 1.5 & $\mathrm{P}$ & $\mathrm{P}$ & $\mathrm{P}$ \\
\hline
\end{tabular}

of the acrylic tapes. Thus, a highly damped deployable solar panel employing constrained layer damping with viscoelastic acrylic tapes is effective for achieving the design goals of launch load attenuation and minimization of the dynamic deflection of the panel at the module level.

\section{Conclusion}

In this study, the demonstration model of a highly damped deployable PCB solar panel module, combined with a pogo pin-based burn wire triggering HRM, was fabricated and experimentally evaluated for use in $3 \mathrm{U}$ CubeSat applications. The proposed solar panel guarantees the structural safety of solar cells under launch vibration environments by reducing the panel dynamic acceleration and deflection through the shear deformation characteristics of adhesive tapes. The optimized design of the pogo pin-based burn wire triggering mechanism has many advantages, including increased loading capability, multiplane constraints, and reliable release action that can overcome the limitations of conventional burn wire cutting release mechanisms. The functionality of the mechanism was verified through solar panel release tests at ambient room temperature. The design effectiveness and structural safety of the solar panel module were experimentally verified in simulated launch and in-orbit environments. The launch vibration results of the solar panel demonstrated that the dynamic displacement along the $z$-axis was reduced significantly by a factor of 46.33 compared with that of a typical solar panel without a stiffener. After all the vibration and TV tests were completed, the visual inspection of the solar panel does not report any crack, dissociation, or plastic deformation on the stiffeners and solar cell coverglass. The release function test of the solar panel, performed after launch vibration and TV tests, revealed the nominal function 
of the mechanism. The test results indicated that the proposed highly damped solar panel module is qualified for use in the CubeSat application.

\section{Data Availability}

The data used to support the findings of this study are available from the corresponding author upon request.

\section{Conflicts of Interest}

The authors declare that there are no conflicts of interest regarding the publication of this manuscript.

\section{Acknowledgments}

This research was supported by a research fund (2020) from Chosun University.

\section{References}

[1] K. Woellert, P. Ehrenfreund, A. J. Ricco, and H. Hertzfeld, "Cubesats: cost-effective science and technology platforms for emerging and developing nations," Advances in Space Research, vol. 47, no. 4, pp. 663-684, 2011.

[2] J. Bouwmeester and J. Guo, "Survey of worldwide pico-and nanosatellite missions, distributions and subsystem technology," Acta Astronautica, vol. 67, no. 7-8, pp. 854-862, 2010.

[3] S. J. Kang and H. U. Oh, "On-orbit thermal design and validation of $1 \mathrm{U}$ standardized CubeSat of STEP cube lab," International Journal of Aerospace Engineering, vol. 2016, 17 pages, 2016.

[4] A. Poghosyan and A. Golkar, "CubeSat evolution: analyzing CubeSat capabilities for conducting science missions," Progress in Aerospace Sciences, vol. 88, pp. 59-83, 2017.

[5] P. Ehrenfreund, A. J. Ricco, D. Squires et al., "The O/OREOS mission-astrobiology in low Earth orbit," Acta Astronautica, vol. 93, pp. 501-508, 2014.

[6] V. Lappas, N. Adeli, L. Visagie et al., "CubeSail: a low cost CubeSat based solar sail demonstration mission," Advances in Space Research, vol. 48, no. 11, pp. 1890-1901, 2011.

[7] X. Li, Q. Schiller, L. Blum et al., "First results from CSSWE CubeSat: characteristics of relativistic electrons in the nearearth environment during the October 2012 magnetic storms," Journal of Geophysical Research: Space Physics, vol. 118, no. 10, pp. 6489-6499, 2013.

[8] D. H. Cho, W. S. Choi, M. K. Kim, J. H. Kim, E. Sim, and H. D. Kim, "High-resolution image and video CubeSat (HiREV): development of space technology test platform using a lowcost CubeSat platform," International Journal of Aerospace Engineering, vol. 2019, 17 pages, 2019.

[9] S. Wu, W. Chen, C. Cao, C. Zhang, and Z. Mu, "A multipleCubeSat constellation for integrated earth observation and marine/air traffic monitoring," Advances in Space Research, 2020.

[10] S. Nag, J. L. Rios, D. Gerhardt, and C. Pham, "CubeSat constellation design for air traffic monitoring," Acta Astronautica, vol. 128, pp. 180-193, 2016.

[11] G. Santilli, C. Vendittozzi, C. Cappelletti, S. Battistini, and P. Gessini, "CubeSat constellations for disaster management in remote areas," Acta Astronautica, vol. 145, pp. 11-17, 2018.
[12] S. Song, H. Kim, and Y. K. Chang, "Design and implementation of 3U CubeSat platform architecture," International Journal of Aerospace Engineering, vol. 2018, 17 pages, 2018.

[13] F. Santoni, F. Piergentili, S. Donati, M. Perelli, A. Negri, and M. Marino, "An innovative deployable solar panel system for CubeSats,” Acta Astronautica, vol. 95, pp. 210-217, 2014.

[14] A. Ampatzoglou and V. Kostopoulos, "Design, analysis, optimization, manufacturing, and testing of a $2 \mathrm{U}$ CubeSat," International Journal of Aerospace Engineering, vol. 2018, 15 pages, 2018.

[15] L. S. Lim, T. D. V. Bui, K. S. Low et al., "VELOX-II: challenges of developing a 6U nanosatellite," in AIAA SPACE 2016, pp. 111, Long Beach, California, September 2016.

[16] T. Y. Park, B. G. Chae, and H. U. Oh, "Development of $6 \mathrm{U}$ CubeSat's deployable solar panel with burn wire triggering holding and release mechanism," International Journal of Aerospace Engineering, vol. 2019, Article ID 7346436, 13 pages, 2019.

[17] S. Lee, A. Hutputanasin, A. Toorian, W. Lan, and R. Munakata, "CubeSat design specification rev. 12," California Polytechnic State University, San Luis Obispo, USA, 2009.

[18] "Innovative Solutions In Space B.V., ISIPOD CubeSat Deployer ISIS-Innovative Solutions in Space," August 2020, https://www.isispace.nl/product/isipod-cubesat-deployer/.

[19] "GOMspace, NanoPower DSP-GOMspace, Deployable Solar Panels for 3U and 6U Satellites," August 2020, https:// gomspace.com/shop/subsystems/power/nanopowerdsp.aspx.

[20] “Solar Arrays-MMA Design LLC," November 2020, https:// mmadesignllc.com/products/solar-arrays/.

[21] A. Thurn, S. Huynh, S. Koss et al., "A nichrome burn wire release mechanism for CubeSats," in Proceedings of the 41st Aerospace Mechanisms Symposium, pp. 479-488, Pasadena, CA, USA, 2012.

[22] A. T. Guzik and O. Benafan, "Design and development of CubeSat solar array deployment mechanisms using shape memory alloys," in Proceedings of the 44th Aerospace Mechanisms Symposium, pp. 1-14, Ohio, 2018.

[23] H. U. Oh and M. J. Lee, "Development of a non-explosive segmented nut-type holding and release mechanism for cube satellite applications," Transactions of the Japan Society for Aeronautical and Space Science, vol. 58, no. 1, pp. 1-6, 2015.

[24] S. Bhattarai, H. Kim, and H. U. Oh, "CubeSat's deployable solar panel with viscoelastic multilayered stiffener for launch vibration attenuation," International Journal of Aerospace Engineering, vol. 2020, Article ID 8820619, 10 pages, 2020.

[25] T. Y. Park, S. H. Kim, H. Kim, and H. U. Oh, "Experimental investigation on the feasibility of using spring-loaded pogo pin as a holding and release mechanism for CubeSat's deployable solar panels," International Journal of Aerospace Engineering, vol. 2018, Article ID 4854656, 10 pages, 2018.

[26] S. Bhattarai, H. Kim, S. H. Jung, and H. U. Oh, "Development of pogo pin-based holding and release mechanism for deployable solar panel of CubeSat," International Journal of Aerospace Engineering, vol. 2019, Article ID 2580865, 13 pages, 2019.

[27] “3M Company, 3M ${ }^{\mathrm{TM}}$ Adhesive Transfer Tape 966," August 2020, https://3m.citrination.com/pif/000314?locale=en-US.

[28] CFE Company, "DIP Spring Pogo Electrical Contact Pins Connector," August 2020, https://www.chttp://feconn.com/ connector/dip-spring-pogo-electrical-contact-pins.

[29] PSA Company, "Resistors-Walsin Technology," August 2020, http://www.passivecomponent.com/products/resistors/. 
[30] “Components101, PC817 Photo-Coupler IC," August 2020, https://components101.com/ics/pc817-ic-pinout-equivalentdatasheet.

[31] Texas Instruments, "SN74LVCIG86 Single 2-Input ExclusiveOR Gate datasheet," August 2020, https://www.ti.com/lit/ds/ symlink/sn74lvc1g86.pdf.

[32] Berkley NanoFil, "Uni-Filament Fishing Line-Berkley Fishing," August 2020, https://www.berkley-fishing.com/berkleyline-uni-filament-berkley-nanofil/berkleynanofil/1285551 .html.

[33] S. C. Kwon, M. S. Jo, D. H. Ko, and H. U. Oh, "Viscoelastic multilayered blade-type passive vibration isolation system for a spaceborne cryogenic cooler," Cryogenics, vol. 105, article $102982,2020$.

[34] ECSS-E-ST-33-01C Rev.2-Mechanisms, Space Engineering Mechanisms, ECSS Secretariat ESA-ESTEC Requirements \& Standards Division, Noordwijk, Netherlands, 2019.

[35] F. Singarayar, R. Reinhard, C. Asma et al., "QB50 system requirements and recommendations," no. 4, pp. 1-28, 2013, June 2020, https://www.qb50.eu.

[36] GEVS: GSFC-STD-7000A, General Environmental Verification Standard (GEVS) for GSFC Flight Programs and Projects, NASA Goddard Space Flight Center, 2013.

[37] M. Malagoli and Y. Allewaert, "Improvement of the wire rating standards based on TV testing and thermal modeling," in Proceedings of the 48th International Conference on Environmental Systems, pp. 1-15, Albuquerque, New Maxico, 2018. 